\title{
The Relationship between Personality Traits and Face Shapes in Chinese Traditional Physiognomy
}

\author{
Zhizhong Kai \\ Factor-Inwentash Faculty of Social Work, University of Toronto, Toronto, Canada \\ Email: kaizhizhong@live.cn
}

How to cite this paper: Kai, Z. Z. (2021). The Relationship between Personality Traits and Face Shapes in Chinese Traditional Physiognomy. Open Journal of Social Sciences, 9, 81-92.

https://doi.org/10.4236/jss.2021.91006

Received: September 3, 2020

Accepted: January 8, 2021

Published: January 15, 2021

\begin{abstract}
Objective: Physiognomy has over 3000 years of history in China, where the belief that personality can be discerned through physiognomy is widespread. However, it hasn't been fully verified by scientific research. Through experiments, this paper explores the relationship between face shape and corresponding personality in physiognomy, and how face shape affects people's judgment of personality. Method: According to the eight face shapes theory of physiognomy, 10 trained laboratory assistants have selected 64 typical faces through 3816 pieces of ID photos following a designated procedure, and tested the selected 64 persons' scores of Cattell's 16 Personality Factors Test. Eight more ID photos have been randomly selected, and each one has been modified by Image Processing Technology into eight face shapes, keeping other facial features same to ensure that the only variable is face shape, and ultimately obtained 64 artificial faces. 949 undergraduates, as participants, have visually judged these 128 faces in a laboratory by using E-prime 2.0 and 16PF Rating Scale. Results: Overall, there was no significant difference of tested sixteen personality traits among eight typical faces. Through a post-hoc test, some face shapes are perceived to have certain significant differences in some personality traits than a certain face shape. For example, on factor Q2 of $16 \mathrm{PF}$, a heart-shaped face $\left(\mathrm{M}=2.625^{*}\right)$ is significantly lower than a diamond-shaped face $(\mathrm{M}=4.375)$. In contrast, there are various differences among the eight face shapes on people's visual judgmental of personality traits. For example, the heart-shaped face $\left(M=4.01^{\star *}\right)$ is significantly lower than all other face shapes on factor A). By comprising the tested personality traits and perceived personality traits of each face shape, there are significant differences among some personality traits (e.g. diamond face on factor $\mathrm{B}, \mathrm{t}=$ $\left.-2.847^{\star *}\right)$. Conclusions: Traditional physiognomy theory which explains personality by face shapes can't be supported by the results. People are af-
\end{abstract}


fected by the inherent stereotype (such as people with square face look like more right-minded), and tend to make a judgment about people's personalities according to stereotypes of face shapes. Although their judgments are inconformity with the real personality traits, it indeed influences many people's judgments on personality. According to this research, if people can tailor their face shape to someone's preferences by using makeup, it will be easier for them to make a good impression with that person.

\section{Keywords}

Face Shape, Visual Cognition, Personality, Physiognomy

\section{Introduction}

From The Oxford English Dictionary (2014): physiognomy is (1a) “a person's facial features or expression (originally frequently considered as indicative of the mind and character)," and (2) "the supposed art of predicting the future from the features of the face."

Chinese beliefs in physiognomy have been dated back to the Zhou Dynasty (1046-256 BCE) (representative writings: Classic of Rites (Fang, 2008)), welldeveloped when in the period of two Han dynasties (206 BC-9 AD) (representative writings: Miscellaneous on Face Features (Xie \& Dong, 2008), Discourse Balance (Wang, Han Dynasty)), and had a prosperous period in Song Dynasty (960-1279) (representative writings: Shen Xiang Quan Bian (Chen, Song Dynasty) and Ma Yi Shen Xiang (Mayi, 1997). The ensuing Tai Qing Shen Jian (Wang, 2009) and Liu Zhuang Shen Xiang (Yuan, Ming Dynasty)) in Ming Dynasty (1368-1644), Bing Jian (Zeng, Qing Dynasty) in Qing Dynasty (1636-1912) are all widespread in China nowadays. However, over 3000 years of development, few scholars have explored the relationship between facial features and personality traits scientifically (Xu, 2008).

The history in western countries of belief and practice of physiognomy can be traced back to ancient Greece, when Aristotle published Physiognomica (see, e.g., Brandt, 1980; Zebrowitz, 1997). In the late eighteenth century and the early nineteenth century, Johann Caspar Lavater's (1797) resoundingly successful book was the historic apex of physiognomy (see, e.g., Hegel, 1931/1967, pp. 337-372) and was welcomed by the general public and scholars of this neglected area (see, Shookman, 1993). Emerging from phrenology, physiognomy originally studied protuberances on the skull in the late nineteenth century (Ran \& Yaacov, 2000). By the end of the 19th century, phrenology was in decline and had been eliminated by science. Early research (see, e.g., Anderson, 1921; Cook, 1939; Thornton, 1943; Secord, 1965; Secord et al., 1953; Secord, Dukes, \& Bevan, 1954; Strich \& Secord, 1956; Albright et al., 1997; Berry, 1990, 1991; Zebrowitz, 1997; Berry \& McArthur, 1985; McArthur \& Apatow, 1984) seemed to suggest an acceptable reliability of physiognomic inferences by experiments, which means in- 
dependent judges reading similar personality from a face. Conversely, early research also showed poor validity and repeatability of physiognomy inferences (see, e.g., Cohen, 1973; Alley, 1988).

Early scientific studies on physiognomy found very little (if any) evidence for a relationship between facial features and personality traits (Cleeton \& Knight, 1924). Whereas early studies examined relationships between isolated facial features and personality (e.g., eye size and impulsiveness, Cleeton \& Knight, 1924), similar results were found throughout most of the 1900s (Alley, 1988). Many studies have now shown that perceptions of personality drawn from single face images, short videotapes, or very brief personal encounters align with the target's self-reported personality (Ambady, Hallahan, \& Rosenthal, 1995; Berry, 1990; Bond Jr., Berry, \& Omar, 1994; Borkenau \& Liebler, 1992a, 1992b, 1993a, 1993b). Roy (2003) even considered physiognomy as an art and pseudoscience. As technology develops, accurate personality judgments can even be made from computer-averaged faces. Penton-Voak, Pound, Little, and Perrett (2006). Further studies have found that facial dimensions are associated with dominance and aggression (facial width-to-height ratio; Carré et al., 2009).

In this paper, physiognomy only refers to identifying personality traits, not includes the part of telling future. Facial features in physiognomy have different categories, such as five main face parts (eyes, eyebrow, ear, mouth, nose), up, middle, lower part of your face, and 12 functional parts of your face $(\mathrm{Xu}, 2011)$. Different facial features (e.g. face shape) can reveal certain meanings in Physiognomy. This paper only uses face shape, one of the facial features, as the object to study whether people with different face shapes will have different personality traits. Meanwhile, this study also investigated how face shape influences people's judgement of their corresponding personality traits.

\section{Research Method}

The whole study consisted of two stages. The first stage was to collect experimental materials, and the second stage was to carry out experiments.

\subsection{Category of Face Shapes}

This study synthesized many books about physiognomy (e.g. Ma Yi Shen Xiang) and finally employed 8 face shapes to categorize, which are oval, round, rectangular, square, triangular, diamond, inverted triangle and heart face shape. This face shape category is extensively applied in practice and seen in many books, and also has clear distinction among each shape (Figure 1).

\subsection{Typical Faces and Tested Personality Traits}

After receiving informed consent, over 4000 new university students from a same university participated in the first stage of the study, which was to complete sixteen personality factor questionnaires (16PF in short) and submit their color electronic ID photo. The measurement of $16 \mathrm{PF}$ was conducted on a class 


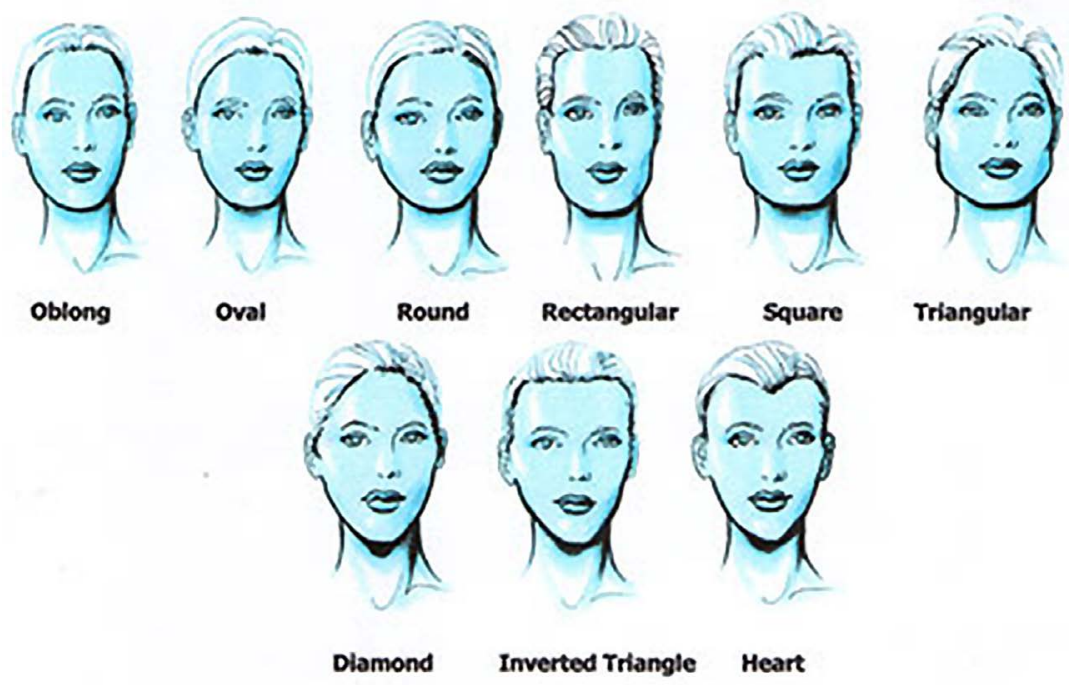

Figure 1. Face shapes categories.

basis and on computer-based software in the computer room. Electronic photos employed the standard identification photo and have been taken in a photo studio. Finally, 3816 photos corresponding to their 16PF scores have been selected based on the criterion of not wearing glasses, no hair covering the face, no makeup, no obvious scar, no obvious mole or birthmark, showing the whole face. Ten assistants attended the training to learn the method of identifying eight different typical faces from all qualified photos, and picked 30 face photos for each type of face shape. Comparing all results of assistants' selections, one photo was selected as typical face if it has been selected by at least seven assistants and above. The above process was repeated until eight photos have been chosen for each face shape for this experiment. Each photo of the typical face has a code (see Figure 2), such as R1 (round face No.1), S5 (square face No.5), and I7 (invert-triangular No.7).

By searching typical faces' student's ID number, the corresponding score of $16 \mathrm{PF}$ has all been found and matched. The reason to select university students' faces as typical faces is because their faces features are obviously well-developed and the skeletal structure has been basically finalized, which can exclude the problem of wrinkles among elder people and baby faces among children or teenagers. Besides this consideration in choosing typical faces, the reason for using $16 \mathrm{PF}$ scores from university students is also because the personalities of university students are basically mature and stable.

\subsection{Artificial Faces}

Although the selected typical faces have the most typical features respectively for eight types of face shape, other facial features still remained on typical faces, such as eye size and nose height. To eliminate the influence of all other facial features, the researcher created artificial faces for the experiment to control the experimental variables. 


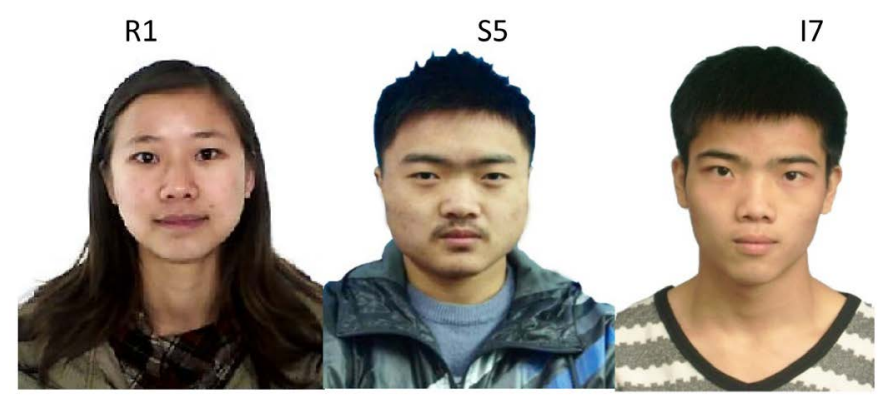

Figure 2. Typical face examples.

The process of creating artificial faces started from original digital human face photos, which were found from searching "ID photo" as keywords in a search engine, such as Google. The criteria for selecting these ID photos are: non-famous people, non-high click photos, average face, without glasses, showing full face, and no copyright. Eight photos (male and female equally) have been randomly chosen from up-to-standard original digital ID photos, and downloaded in a highquality JPG file format. Then in Photoshop software, each of these eight ID photos was reshaped into eight different face shapes ( 8 ID photos $\times 8$ face shapes $=64$ pieces in total) by deleting the hair and ears, leaving remaining the facial features unchanged. As is seen from the samples in Figure 3, the only variable is face shape, while other facial features were made uniform.

\subsection{Participants in the Second Stage of the Study}

In order to get a big sample, the experiment in the second stage applied classbased group testing. To prevent participants who would potentially know the person in the typical face, all participants were recruited from another university to assess the personality traits of the typical faces and artificial faces. Based on the principle of convenience sampling and their curriculum schedule, 949 university students ( 18 to 25 years old, $\mathrm{M}=21.63, \mathrm{SD}=1.821$ ) participated in the study $($ male $=405,42.7 \%$; female $=544,57.3 \%)$.

\subsection{Experiment Process}

The experimental process was conducted in a computer laboratory with E-prime program in every computer. In each experimental trial, the participants from the same class entered the laboratory with an appointment and every participant received an evaluation manual. The experimenter started to read out the experimental instruction: "This is a psychological experiment about personality traits judgment. Please open the evaluation manual in your hand and score on the correspondence page when you evaluate each face later. There is no right or wrong about personalities here. You will score in sixteen dimensions for each face. Please read carefully the instruction on the first page in the manual and make sure you understand the description of every personality dimension. You are welcome to ask questions if you don't understand." If participants clearly 


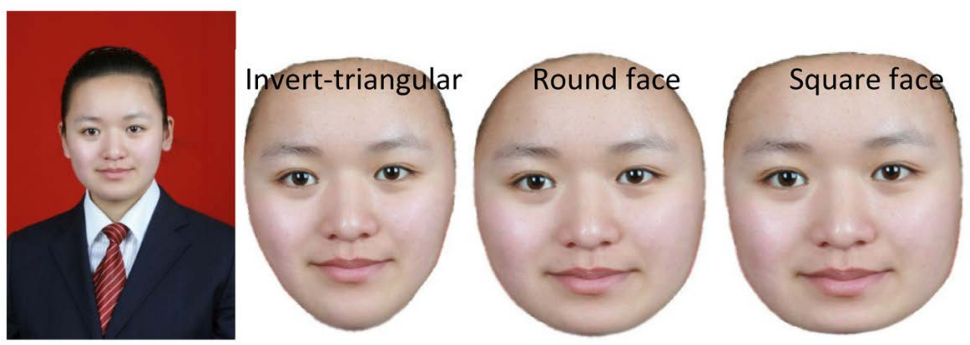

Figure 3. Sample images of artificial faces.

understood, the experimenter would say "please judge their personalities according to the face being shown. Each face has sixteen dimensions for you to judge and please circle the corresponding number in the middle column of the form. You only have two minutes to rate each face, so use your intuition." After the experiment finished, the participant is welcome to leave after handing in the manual (Figure 4).

Based on the experimental design, there would be 128 faces ( 8 face shapes $\times 8$ typical faces +8 artificial faces $\times 8$ face shapes) that need to be judged, which will take 256 minutes to complete. To shorten the experiment time, every trial and every participant was regularly arranged to judge 16 faces ( 8 artificial faces and 8 typical faces between guidance words and ending black screen) by using the method of permutation and combination, which will take 32 minutes in total.

\subsection{Evaluation Manual}

The researcher created an evaluation manual for personality traits judgment. Every face with a specific code, which had a same code on the manual, was displayed on the computer screen. In addition, every page was composed of a personality profile table (including sixteen personalities' traits descriptions) adopting from 16 Personality Factors Questionnaire (Russell \& Karol, 2002). The first page required demographic information from participants, such as gender and age. The cover page showed the instructions for the experiment.

\section{Results}

\subsection{The Personality Profile of Eight Face Shapes from Typical Faces}

From the above figure, it is apparent that the personality profiles of the different face shapes were generally similar and even overlapped on some factors. Most of the face shapes had one or more personality traits that significantly differed from other face shapes. Based on the results from post-hoc test of variance analysis, these significant differences have been circled in Figure 5. The inverted triangular face and rectangular faces were not significantly different from any other face shape in any of the 16 personality traits. However, on the whole, no one face shape was significantly different from all others in any one personality trait. 


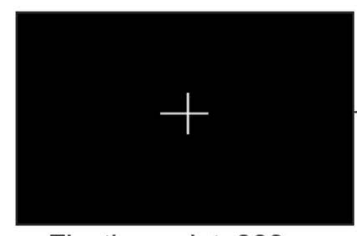

Fixation point: $300 \mathrm{~ms}$

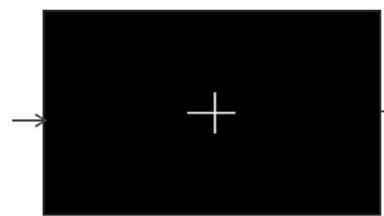

Fixation point: $200 \mathrm{~ms}$

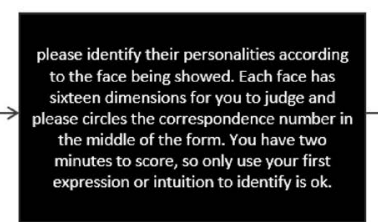

Instruction: click to begin

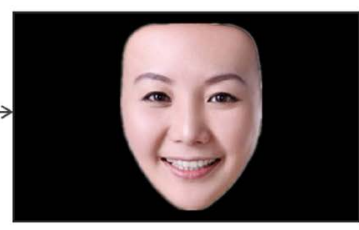

Stimulus: $2 \mathrm{~min}$

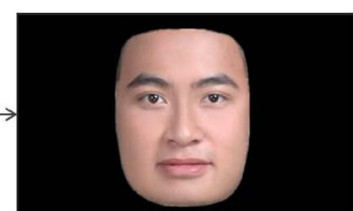

Stimulus: 2 min Each trial is a permutation and combination of faces, includes a set of 8 Typical Faces and 8 Artificial Faces

Figure 4. Experimental process.

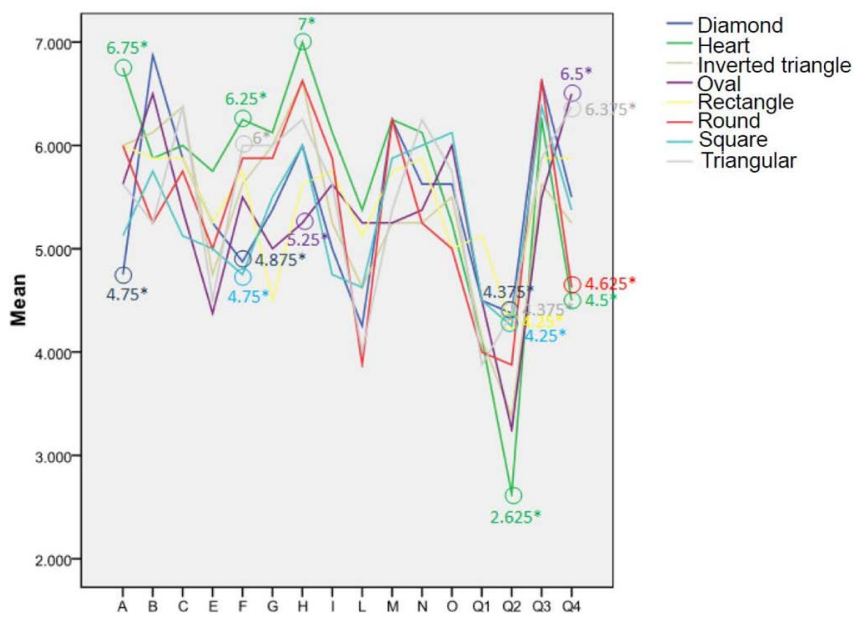

Figure 5. The personality profile of eight face shapes from typical faces.

\subsection{The Assessed Personality Profile of Eight Face Shapes from Artificial Faces}

Compared to the result 3.1, the personality traits of eight face shapes are significantly different from each other in the participants' eyes. Each face shape was assessed to have certain personality traits that differed from all other face shapes, which have been circled in Figure 6.

\subsection{The Difference between the Tested and Assessed Personality of Each Face Shape from Typical Faces}

For each face shape from typical faces, the researcher compared 16 tested personality traits with assessed personality traits, and listed all the significantly different traits for each face shape in the table above. Some face shapes showed significant differences between perceived personality (assessed personality) and real personality (tested personality), such as the inverted triangular face and the square face. For other face shapes, people's judgments of personality traits closely matched the tested results, such as with the triangle face (Table 1). 

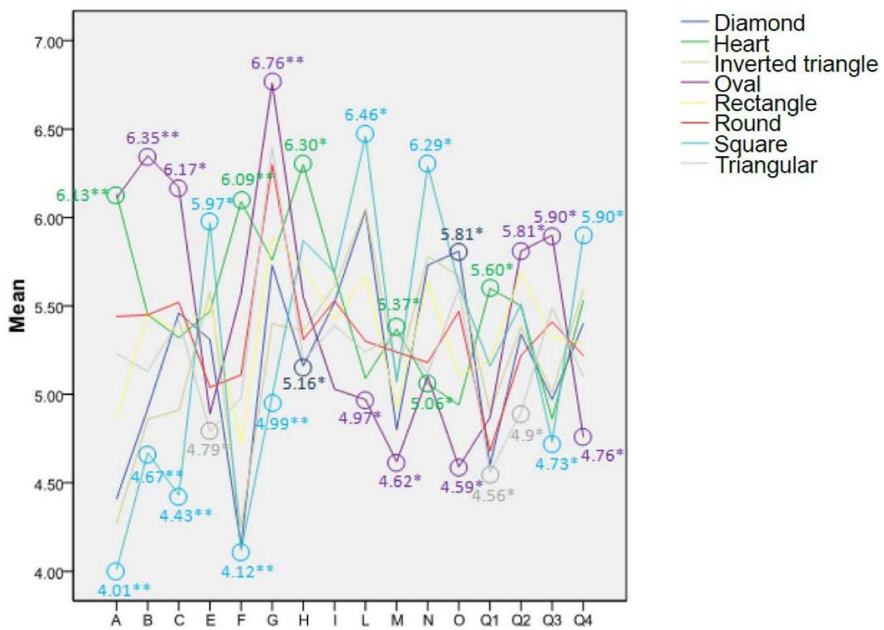

Figure 6. The personality profile of eight face shapes from artificial faces.

Table 1. The difference between the tested and assessed personality of each face shape.

\begin{tabular}{|c|c|c|c|c|}
\hline Face shapes & PF & T value & Assessed personality & Tested personality \\
\hline \multirow{3}{*}{ Diamond } & B & $-2.847^{\star \star}$ & Looks intelligent & but less intelligent \\
\hline & $\mathrm{L}$ & $2.256^{*}$ & Looks trusting & but distrustful \\
\hline & Q3 & $-2.182^{*}$ & Looks perfectionistic & but flexible \\
\hline \multirow{3}{*}{ Heart } & Q1 & $3.640^{* *}$ & Looks traditional & but open to change \\
\hline & Q2 & $3.586^{* \star}$ & Looks affiliative & but solitary \\
\hline & Q3 & $-4.339^{* *}$ & Looks perfectionistic & but flexible \\
\hline \multirow{6}{*}{ Inverted triangle } & A & $-3.412^{\star *}$ & Looks warm & but cool \\
\hline & $\mathrm{C}$ & $-2.713^{*}$ & Looks emotionally stable & but less stable \\
\hline & $\mathrm{F}$ & $-5.039^{\star *}$ & Looks lively & but serious \\
\hline & $\mathrm{H}$ & $-3.307^{*}$ & Looks socially bold & but shy \\
\hline & $\mathrm{L}$ & $3.718^{\star *}$ & Looks trusting & but distrustful \\
\hline & Q2 & $4.696^{\star *}$ & Looks affiliative & but solitary \\
\hline \multirow{5}{*}{ Oval } & $\mathrm{C}$ & $2.929^{*}$ & Looks emotionally stable & but stable \\
\hline & G & $2.376^{\star}$ & Looks disregard rules & but rule-conscious \\
\hline & $\mathrm{O}$ & $-3.667^{\star *}$ & Looks apprehensive & but unworried \\
\hline & Q2 & $6.862^{\star *}$ & Looks affiliative & but solitary \\
\hline & Q4 & $-5.180^{\star *}$ & Looks tense & but relaxed \\
\hline \multirow{3}{*}{ Rectangular } & A & $-2.404^{*}$ & Looks warm & but cool \\
\hline & $\mathrm{F}$ & $-2.745^{\star}$ & Looks lively & but serious \\
\hline & Q2 & $3.867^{\star \star}$ & Looks affiliative & but solitary \\
\hline \multirow{2}{*}{ Round } & $\mathrm{L}$ & $2.572^{\star}$ & Looks trusting & but distrustful \\
\hline & M & $-2.708^{\star}$ & Looks abstract & but grounded \\
\hline \multirow{5}{*}{ Square } & $\mathrm{E}$ & $3.467^{*}$ & Looks deferential & but dominant \\
\hline & I & $2.501^{\star}$ & Looks no-nonsense & but sensitive \\
\hline & $\mathrm{L}$ & $2.159^{\star}$ & Looks trusting & but distrustful \\
\hline & Q2 & $2.734^{\star}$ & Looks affiliative & but solitary \\
\hline & Q3 & $-3.259^{\star}$ & Looks perfectionistic & but flexible \\
\hline Triangular & $\mathrm{F}$ & $-3.033^{*}$ & Looks lively & but serious \\
\hline
\end{tabular}




\section{Discussion}

\subsection{Whether Traditional Physiognomy Is Reliable}

Result 3.1 showed that different face shapes were not associated with any particular personality traits. The Spearman rank correlation also showed that there is only a slight correlation between face shape and factor B (intelligence) $(r=-0.247$, $\mathrm{P}=0.049$ ). In other words, the traditional physiognomy theory does not seem to hold water. Traditional physiognomy often says: people with round faces are gentle and smooth, easy to get along with, that those with oval faces have good compliance, while those with square faces have strong willpower and an extroverted personality, and those with inverted triangular faces lack mobility and so on (Livia, 1986), which cannot be seen in the results based on experimental data in this study.

In Figure 5, the personality profiles of various face shapes are similar. This phenomenon may be because the participants got the $16 \mathrm{PF}$ questionnaire score by completing questions about how to evaluate their own behavior and attitude. Most people tend to bring out the better side of themselves to fit society's expectations. Therefore, many participants got a similar score of the 16PF questionnaire. In a later experiment, the participants were asked to rate personality traits by looking at other people's faces. This setup allowed participants in later experiments to freely evaluate others' personalities without considering social expectations. This is the limitation of this experiment. Also, it's inevitable for this error if the experiment employing a traditional psychological measurement.

\subsection{Judging Personality from Faces in Modern Days}

As result 3.2 reveals to us, people already stereotype each face shape. The reason is not only coming from the effect of traditional physiognomy theory, but also comes from everyone's daily life experience, as well as the associations of each face shape's appearance. For instance, people normally associate square faces, also called "Guo Zi Lian" in China, with responsible, strong and upright personality traits. The study also found that the high score traits and low score traits combination for each face shape, which is meanwhile stereotype the face shape coming from people (Table 2 ).

Table 2. High score traits and low score traits combination for each face shape.

\begin{tabular}{cccccc}
\hline & $\begin{array}{c}\text { High } \\
\text { score } \\
\text { traits } \\
\text { Face shape }\end{array}$ & $\begin{array}{c}\text { Low } \\
\text { score } \\
\text { traits }\end{array}$ & Face shape & $\begin{array}{c}\text { High } \\
\text { score } \\
\text { traits } \\
\text { combination } \\
\text { combination }\end{array}$ & $\begin{array}{c}\text { Low } \\
\text { score } \\
\text { traits } \\
\text { Diamond face }\end{array}$ \\
L O N & F A Q1 & Rectangular face & G H Q2 & F A M \\
Heart face & H A F & Q3 O N & Round face & G I C & Q1 E F \\
Inverted Triangle face & L N O & F A B & Square face & L N E & A F C \\
Oval face & G B C & O M Q4 & Triangle face & G O Q3 & Q1 E Q2
\end{tabular}




\section{Implication and Limitations}

This is an era of looking at faces. Even if we can't find the evidence that directly relates to face shape and personality, however, we found that people still make judgments on others' personality according to their face shapes, which is consistent with those of previous study (Todorov, Said, \& Verosky, 2011). As the Chinese saying goes, we "judge people with their appearance". Whether or not we are correct to do so (as showed in the result that at least $21.9 \%$ of the time it is not correct), this prediction already makes the first impression for us when we see others at the first sight. This finding can be well applied in daily life, for instance, using makeup techniques such as highlighter and shadow powder to change your face shape according to different occasions and other people's preference, will enable us to easily get trust and build a relationship. Especially in the scenarios of blind dates or interviews, we will have more advantages by doing in this way.

This study has some limitations. First, the sample size isn't big enough to represent the population of a national norm. Second, it is not enough to exclude the influence of other facial features on the experimental results through the subjective evaluation of 10 laboratory assistants. Third, the typical faces and artificial faces in the study are all Asian faces, which cannot well cover the features of face shape from other ethnicities. Therefore, follow-up research needs to improve in these areas.

\section{Conflicts of Interest}

The author declares no conflicts of interest regarding the publication of this paper.

\section{References}

Albright, L., Malloy, T. E., Dong, Q., Kenny, D., Fang, X., Winquist, L., \& Yu, D. (1997). Cross-Cultural Consensus in Personality Judgments. Journal of Personality and Social Psychology, 72, 558-569. https://doi.org/10.1037/0022-3514.72.3.558

Alley, T. R. (1988). Social and Applied Aspects of Face Perception: An Introduction. Hillsdale, NJ: Erlbaum.

Ambady, N., Hallahan, M., \& Rosenthal, R. (1995). On Judging and Being Judged Accurately in Zeroacquaintance Situations. Journal of Personality and Social Psychology, 69, 518-529. https://doi.org/10.1037/0022-3514.69.3.518

Anderson, L. D. (1921). Estimating Intelligence by Means of Printed Photographs. Journal of Applied Psychology, 5, 152-155. https://doi.org/10.1037/h0075189

Berry, D. S. (1990). Taking People at Face Value: Evidence for the Kernel of Truth Hypothesis. Social Cognition, S, 343-361. https://doi.org/10.1521/soco.1990.8.4.343

Berry, D. S. (1991). Accuracy in Social Perception: Contributions of Facial and Vocal Information. Journal of Personality and Social Psychology, 6, 298-307. https://doi.org/10.1037/0022-3514.61.2.298

Berry, D. S., \& McArthur, L. Z. (1985). Some Components and Consequences of a Babyface. Journal of Personality and Social Psychology, 48, 312-323.

https://doi.org/10.1037/0022-3514.48.2.312 
Bond Jr., C. F., Berry, D. S., \& Omar, A. (1994). The Kernel of Truth in Judgments of Deceptiveness. Basic and Applied Social Psychology, 15, 523-534. https://doi.org/10.1207/s15324834basp1504_8

Borkenau, P., \& Liebler, A. (1992a). The Cross-Modal Consistency of Personality: Inferring Strangers Traits from Visual or Acoustic Information. Journal of Research in Personality, 26, 183-204. https://doi.org/10.1016/0092-6566(92)90053-7

Borkenau, P., \& Liebler, A. (1992b). Trait Inferences: Sources of Validity at Zero Acquaintance. Journal of Personality and Social Psychology, 62, 645-657. https://doi.org/10.1037/0022-3514.62.4.645

Borkenau, P., \& Liebler, A. (1993a). Consensus and Self-Other Agreement for Trait Inferences from Minimal Information. Journal of Personality, 61, 477-496. https://doi.org/10.1111/j.1467-6494.1993.tb00779.x

Borkenau, P., \& Liebler, A. (1993b). Convergence of Stranger Ratings of Personality and Intelligence with Self-Ratings, Partner Ratings, and Measured Intelligence. Journal of Personality and Social Psychology, 65, 546-553.

https://doi.org/10.1037/0022-3514.65.3.546

Brandt, A. (1980). Face Reading: The Persistence of Physiognomy. Psychologist Today, 90, 90-96.

Carré, J. M., McCormick, C. M., \& Mondloch, C. J. (2009). Facial Structure Is a Reliable Cue of Aggressive Behavior. Psychological Science, 20, 1194-1198. https://doi.org/10.1111/j.1467-9280.2009.02423.x

Chen, C. (Song Dynasty). 神相全编[Shen Xiang Quan Bian] (Z. Jin, Trans.). Beijing: World Affairs Press, 2013: 11.

Cleeton, G., \& Knight, F. B. (1924). Validity of Character Judgments Based on External Criteria. Journal of Applied Psychology, 8, 215-231. https://doi.org/10.1037/h0072525

Cook, S. W. (1939). The Judgment of Intelligence from Photographs. Journal of Abnormal and Social Psychology, 34, 384-389. https://doi.org/10.1037/h0054598

Fang, X. D. (2008). 大戴禮記匯校集解[Classic of Rites]. Beijing: Chung Hwa Book Company Limited.

Hegel, G. W. F. (1967). The Phenomenology of Mind (J. B. Baillie, Trans.). New York: Harper Torchbooks. (Original Work Published 1931)

Lavater, J. (1797). Essays on Physiognomy (C. Moore, Trans.). London: H. D. Symonds.

Livia, K. K. (1986). A Textbook of Physiognomy: The Tradition of the Shenxiang Quanbian. Asian Folklore Studies, 45, 227-258. https://doi.org/10.2307/1178619

Mayi Daozhe. (1997). 图解式麻衣神相[Graphic Mayishenxiang]. Zhengzhou: Zhongzhou Guji Publishing Company.

Penton-Voak, I. S., Pound, N., Little, A. C., \& Perrett, D. I. (2006). Personality Judgments from Natural and Composite Facial Images: More Evidence for a "Kernel of Truth" in Social Perception. Social Cognition, 24, 607-640.

https://doi.org/10.1521/soco.2006.24.5.607

Ran, H., \& Yaacov, T. (2000). Facing Faces: Studies on the Cognitive Aspects of Physiognomy. Journal of Personality and Social Psychology, 78, 837-852. https://doi.org/10.1037/0022-3514.78.5.837

Roy, P. (2003). “Marginalized Practices”, The Cambridge History of Science: EighteenthCentury Science. The Cambridge History of Science, (4 Illustrated ed.). Cambridge University Press, 495-497.

Russell, M. T., \& Karol, D. (2002). The 16PF Fifth Edition Administrator's Manual. Champaign, IL: Institute for Personality and Ability Testing. 
Secord, P. (1965). Facial Features and Inference Processes in Interpersonal Perception. In R. Taguiri \& L. Petrullo (Eds.), Person Perception and Interpersonal Behavior (pp. 300-315). Stanford, California: Stanford University Press.

Secord, P. F., \& Bevan, W. (1956). Personalities in Faces: III. A Cross Cultural Comparison of Impressions of Physiognomy and Personality in Faces. Journal of Social Psychology, 43, 283-288. https://doi.org/10.1080/00224545.1956.9919224

Secord, P. F., Bevan, W., \& Dukes, W. F. (1953). Occupational and Physiognomic Stereotypes in the Perception of Photographs. Journal of Social Psychology, 37, 261-270.

Secord, P. F., Dukes, W. F., \& Bevan, W. (1954). Personalities in Faces: I. An Experiment in Social Perceiving. Genetic Psychology Monographs, 49, 231-279.

Shookman, E. (Ed.) (1993). The Faces of Physiognomy: Interdisciplinary Approaches to Johann Caspar Lavater. Columbia, SC: Camden House.

Thornton, G. R. (1943). The Effect upon Judgments of Personality Traits of Varying a Single Factor in a Photograph. Journal of Social Psychology, 18, 127-148. https://doi.org/10.1080/00224545.1943.9921704

Todorov, A., Said, C. P., \& Verosky, S. C. (2011). Personality Impressions from Facial Appearance. In A. Calder, J. V. Haxby, M. Johnson, \& G. Rhodes (Eds.), Handbook of Face Perception (pp. 631-652). Oxford University Press. https://doi.org/10.1093/oxfordhb/9780199559053.013.0032

Wang, P. (2009). 图解太清神鉴[Graphic Taiqingshenjian]. Beijing: Hua Ling Publishing Company.

Wang, Y. (Han Dynasty). 论衡校注[Lun Heng Jiao Zhu] (Z. Zhang, Trans.). Shanghai: Shanghai Ancient Books Publishing House, 2010.

Xie, L. J., \& Dong, P. W. (2008). 中国古代相术[Ancient Chinese Physiognomy]. Beijing: Jiuzhou Press.

$\mathrm{Xu}$, W. Q. (2011). 图解相术[Graphic Physiognomy]. Xi'an: Shaanxi Normal University Press.

Xu, Z. Y. (2008). 相术: 是科学还是迷信一一从意大利犯罪学家龙勃罗梭的著作《犯罪 人论》入手[Physiognomy: Science or Superstition-From the Writings of the Italian Criminologist Lombroso]. Consume Guide, 2, 181.

Yuan, L. Z. (Ming Dynasty). 柳庄神相[Liuzhuang Shenxiang] (Z. Jin, Trans.). Beijing: World Affairs Press, 2013.

Zebrowitz, L. A. (1997). Reading Faces: Window to the Soul? Boulder, CO: West View Press.

Zeng, G. F. (Qing Dynasty). 冰鉴[Bingjian]. Beijing: China Pictorial Publishing House, 2011. 